\title{
Affecting phantasm: The genesis of Pakistan in The Heart Divided
}

\author{
Humaira Saeed* \\ University of Manchester, $U K$
}

*Email: humaira.saeed@manchester.ac.uk

This article explores the Partition narrative put forward by Mumtaz Shah Nawaz's novel The Heart Divided (1948), which is set in 1930s and 1940s colonial India. It argues that the novel's teleological narrative proposes both the inevitability and desirability of Pakistan as it emerged from and through nationalist liberation movements for Indian independence. It utilizes theories of affect to illuminate the ways in which affects of belonging power much of the drive for the creation of Pakistan in the novel, and are used to consolidate a sense of Hindu-Muslim difference. The article furthermore proposes that emotions exist in tension with bureaucracy, and that affects of belonging to the nation repress the violence that characterized Partition. The analysis engages with the novel as a Partition narrative that does not address the human cost of Partition.

Keywords: Partition of India; affect; nationalism; Pakistan; Mumtaz Shah Nawaz; The Heart Divided

This article takes as its starting point the proposition that the existence of Pakistan was confirmed through both nationalist sentiment and bureaucratic process. I consider this nationalist sentiment as one generated in 1930s and 1940s colonial India, and mobilized around the construction of Muslims as a separate collective to other communities in India, primarily Hindus. This was a non-territorialized Muslim nation, defined by the Muslim League using the two-nation theory, which insisted on Hindus and Muslims being two separate nations in terms of identity and interest. As the British Raj withdrew in August 1947, two independent postcolonial nations were established: the geographical borders of each was delineated by Sir Cyril Radcliffe and primarily based on colonial census data. ${ }^{1}$ Muslim-majority areas were awarded to Pakistan and Hindu-majority areas to India. This bureaucratic process defined the geographical parameters of Pakistan, and led to millions migrating across the new borders. Partition was also characterized by the extreme human cost of mass dislocation and violence. In this article I reflect on the ways that Mumtaz Shah 
Nawaz's novel The Heart Divided foregrounds the emotions of nationalism without addressing Partition's bureaucratic dimension and human cost.

Heart narrativizes Muslim perspectives, and my argument maintains this focus in order to analyse the trajectory that emerges between Muslim identity and attachment to the nation of Pakistan. Set in 1930s-1940s Lahore in colonial India, the novel follows the lives of an elite Muslim family, the Jamaluddins, centring on three siblings: Habib, Sughra and Zohra. Using the political beliefs and activism of the main characters, the novel makes a case for Pakistan's creation, and is persuasive regarding the necessity of the nation's becoming. Sughra is a campaigner for the rights of Muslim women, and member of the Muslim League. Habib and Zohra are both Indian nationalists who are persuaded during the course of the novel of the legitimacy of the Muslim League and the idea of Pakistan. My contention is that this political trajectory is facilitated by the effectiveness of emotions and affective attachments in mobilizing individuals into a collective, and in naturalizing difference between Hindu and Muslim communities. Embedded in Heart's foregrounding of nationalist emotion is the absence of the role of bureaucratic process in defining the nation this absence enables an avoidance of the contradictions of Partition and the human costs it entailed.

\section{The Heart Divided and the Partition genre}

Mumtaz Shah Nawaz was part of an elite activist family, and was involved in the All India Congress and then the Muslim League; she completed The Heart Divided in 1948, the year of her death. The novel was not published by Shah Nawaz's family until 1959 and is often not considered in terms of literary merit due to its being unedited before her death. Critic Muneeza Shamsie has commented that the novel 
"has great socio-political significance but clearly needed much more work" (2005, xi). The socio-political significance of the novel can be understood by virtue of its having been written in close proximity to the time it charts; for this reason it offers an immediate working-through of steps toward Pakistan and Partition. This also points to the novel's particularity, as the majority of novels that deal with Partition and the politics that preceded it are written from a more reflective position.

Heart acts as a justification for Partition by offering a rationale for Pakistan, yet does not feature Partition directly, as the narrative ends before Partition took place. In the light of this tension, I want to consider what the implications are of reading Heart as "Partition fiction". ${ }^{2}$ Partition literature often charts a happy and peaceful coexistence of communities before Partition, juxtaposed with the violence and dislocation of 1947. An obvious comparison to Heart is Attia Hosain's better-known Sunlight on a Broken Column (1961). Like Heart, Sunlight covers the pre-Partition time, addresses the impact of the period on individuals and their relationships, and is also centred on an elite Muslim family. Sunlight is the only canonical Muslim novel in the genre of what we might term Partition fiction. The two novels use emotions in very different ways in relation to Partition's bureaucratic dimension. In Sunlight, the emotions function as motivation for maintaining connections across difference and borders, whereas in Heart they are used to justify separation. Whereas Sunlight covers the time that came after Partition, and is therefore more able to reflect the enormity of the violence that ensued before, during and after Partition, Heart represses this story. Although it charts recent history, Sunlight offers the benefit of hindsight, through which the full implications of the borders drawn can be expressed. Heart, written before the work of reflection could be done, offers insights into the demands of 
nationalism and the need to justify the creation of Pakistan at its moment of emergence.

Where narratives of Partition focus on the human dimension, the story of the nation and of national politics is not always included. The particular narrative of Heart works to normalize Partition's processes in a way that much Partition fiction does not, primarily because it approaches Partition by way of a discussion of human relationships as they are understood by and through national politics. Political events and contexts are as central to the story as the characters, and emotions are not simply inter-personal, but also reflective and constitutive of national politics.

Affect and the emotions have been used to good effect when theorizing nationhood, in particular the felt experience of national belonging, the emotional legitimacy of the nation, and the exclusions these engender. ${ }^{3}$ Don Handelman has persuasively argued for the nation-state's reliance on both bureaucratic logic and national emotion for its existence. He posits that the nation-state embodies the Cartesian mind-body split whereby governance and administration (bureaucracy) reflect the reason of the mind, and nationalism the emotions of the body $(2007,120$ 121). Partha Chatterjee has discussed a similar division in relation to the nationalist novels of the 19th-century Bengali writer Bankim. He outlines how Bankim's work has often been interpreted as reflecting a "tussle between rationalism and an emotionalism, a conflict of the mind and the heart" whereby the author's mind was attracted to the rationality of the European Enlightenment, while his heart remained aligned with a glorious Hindu past $(2001,80)$. What both critics point to are the ways in which a rational concept of the nation exists alongside more emotive affiliations, even where these are in tension. For Chatterjee, the tensions that arise are indicative of the contradictions of the nationalist project itself. Within the context of the 
decolonization of the Indian subcontinent charted in Heart, a tension emerges between the idea of Pakistan, that is supported by belonging and pride, and its materiality, that is realized through borders based on colonial census data. The investment of Heart in the emotions, and the absence of the bureaucratic dimension of Pakistan's creation, allow the narrative to ignore this tension: the contradictions within the nationalist project remain unaddressed.

\section{The affective turn to Pakistan}

Lawrence Grossberg has proposed that a consideration of affect is required to adequately understand the effectiveness of ideology (1992, 82-83). Affect becomes a central mechanism by which the Muslim League, and its developing nationalist ideology, garners support within the novel. Emotions can generate what Lauren Berlant has termed "intimate publics" -- spaces charged by affective investments in "better lives" (2008, viii). Berlant advances this structure in relation to commodity culture in the USA, yet her formulation is extremely productive beyond this context. As she outlines, the intimate public draws people together via a sense of commonality that is located in history but generates belonging within the present. The temporal implication of the intimate public also extends into the future by promising an even better social (or collective) belonging as a result of participation in this intimate public (2008, viii). It is my contention that Heart charts Pakistan as an intimate public that exists phantasmatically in the hearts of many before it is articulated as geographical space, and that this space is actually generated due to its beginnings in the heart. In the novel, affective attachments to a glorious Islamic heritage and ideals of liberty are shown to motivate the characters' involvement in the Muslim League and to generate support for the League from the urban poor, which leads to an 
investment in the goal of Pakistan. That Pakistan does become a nation delineated by geographical borders suggests that sentimental investments are not only generated in relation to existing nations, but can produce (maintain and alter) the bureaucratic articulation of nations.

For Berlant, participants in the intimate public feel that it expresses their commonality -- a likeness that stems from their history and ongoing attachments. This public, then, becomes a way for them to join together $(2008,5)$. Heart shows the emotional appeal of becoming part of the Muslim League, which draws on narratives of a glorious Muslim history. This use of history asks that Indian Muslims both identify with this glorious past and invest in the promise of a return to glory in the future, constructing the idea of the better experience of social, or collective, belonging that can be attained under the aegis of the League. Elder sister Sughra's participation in politics takes her to New Delhi for a Muslim League conference where, in his speech, a member of the League also utilizes images of glorious Muslim history:

$[\mathrm{H}]$ ave you forgotten your past? Cannot the walls of the Red Fort and the minarets of the Shahi Mosque remind you of the glory that once was yours? [ ... ] Awake! Arise, unite and break your chains for no Muslim can be a slave and live! (2004, 321-322)

This speech interpellates the listener as one who once had glory and has an entitlement to its return. The urgency in the speech works as a call to arms to Muslims, and equates being Muslim with action. This identification with those who feel powerless creates a sense of possibility, and, crucially, this possibility is created through religion. What I am suggesting is that calling people into action as Muslims sets the foundations for the call for Pakistan. Although this is being done in the service of an independent India, the primary affiliation is being a free Muslim within 
India. This association becomes easily transferable to being a free person of a Muslim state. Declarations such as "The foundations of democracy lie in the Islamic way of life" $(2004,275)$ and "for Islam made all men realize they were equal before God" (327) are made by eminent activists in the novel. By focussing on history and the progressiveness of Islam, these declarations give the justification necessary for numerous Muslims to join the Muslim League's struggle for independence. Speeches to Muslim women in the slums also outline the strength and successes of "Muslim women in the old days" $(2004,272)$. Islam becomes the site of investment for "better lives" and more democratic structures, as it engenders a sense of collectivity based on a shared pride in a shared history. ${ }^{4}$ The affective power of religion is utilized in speech-making and generates a communal identity mobilized around religion. As a claim based on religious identity it puts into place the two-nation theory, which asserted Muslims and Hindus as distinct peoples who represented separate nations. In the novel this sense of affective unity creates the collective that can then lay claim to nationhood.

\section{Unity and the consolidation of difference}

One of the ways in which the novel upholds the thesis that Hindus and Muslims are two separate nations is through framing certain affective attachments as plausible and others as not. Romantic relationships become a vehicle whereby the novel communicates how Hindu-Muslim difference is understood; the politics of intimacy are framed as expressions of, and rehearsals for, broader politics. Although the central characters set up a united India as the ideal political goal, they continually insist upon the impossibility of the romantic union between the eldest Jamaluddin sibling, Habib, and the family's close Hindu friend Mohini. The failure of the relationship is 
interpreted by characters as proof that differences between the two communities are insurmountable and natural. The representation of Hindu-Muslim romantic union as implausible, regardless of individual feelings to the contrary, suggests that while there may be desire for Hindu-Muslim unity, this is not practical at a national and collective level.

The moments of tentative intimacy between Habib and Mohini are often expressed in metaphorical terms, with assertions of their respective commitment to Hindu-Muslim unity and Indian independence signalling and developing their romantic feelings for one another. Mohini expresses her commitment to Habib thus:

if we are to be a free country, we must break down these walls that divide our people. [ ... ] You are not merely you, and I'm not just I. We represent two parts of a great people. Two parts that must harmonize and pull together if we are to gain freedom. $(2004,167)$

Mohini's declaration not only places emphasis on the necessity of unity across difference, but also on their symbolic positioning in relation to this goal. In their relationship we not only see the parallels between their interpersonal relations and the larger political framework, but also how their relationship symbolizes politics at the national level. They do not simply refer to Hindu-Muslim unity as allegory; they actually are Hindu-Muslim unity. In Mohini's terms the couple are not two different people but "two parts that must harmonize and pull together". Here the two parts are constituent of India, and unity of these would mean independence and freedom. Ultimately, their union is not consummated, due to the disapproval of their families, who have a less idealized view of the possibilities of their relationship, and due to Mohini's subsequent ill health, which leads to her death. The novel's trial run of Hindu-Muslim unity through the microcosm of a couple can be seen to fail because 
Habib and Mohini's relationship is not allowed by their context. As evidenced by Mohini's death, their cross-religion union is also framed as unhealthy to the individual, since the associated stresses makes her ill. The romantic relationship thus comes to stand in for national affiliation: while the novel does not deny the affective bonds between Hindus and Muslims, it does deny the sustainability of these bonds.

Habib and Mohini's friends and families call on a historicized understanding of relationships across difference, providing historical precedents as proof that the couple's relationship is destined to fail. In so doing, they suggest that affective attachment between the communities has never been plausible. In relation to historicization, Joan Scott (1991) has warned against naturalizing difference and treating it as fact, instead of addressing how the idea of difference constitutes subjects. In the novel, history becomes the evidence that "proves" that the difference between Hindus and Muslims is fixed and as such precludes unity. When considering the relations between Hindus and Muslims in villages, Rajindar asks Sughra:

"surely the common people on both sides should be able to come together. They have lived together in the villages for hundreds of years." "But they have never mixed and mingled," said Sughra. "In some places they don't even eat together and there's no inter-marriage ---’[ ... ]. $(2004,263)$

Here a stark distinction is being made between people who co-habit a space and those who have united. The lack of inter-marriage that Sughra identifies suggests -- or rather proves -- that there is not the requisite intermingling required for unity at the national level. What she proposes is that there is an abstract majority of Muslims and Hindus who do not mix and mingle, and therefore those who do mix cannot be understood as representative of the country. Mohini's father also outlines the needs of an abstract collective that must be considered, saying to her: 
I fear you are an idealist. [ ... ] You see visions of a world that does not exist. [ ... ] Not that I don't believe in these ideas; we all do, and where is the thinking man who does not long for your visionary world? But reality is reality. We live among human beings and we cannot ignore their feelings and prejudices. $(2004,187)$

In this speech, he pits emotions against emotions. Mohini's idealism is marginalized when set against the feelings of "human beings", which are prioritized. It is the feelings of this abstract collective of human beings to which they must adhere. The older generation thus frames Mohini and Habib's desires as naive, as the hopes of a small minority, as against the assumed investments and attitudes of "reality" or the "many", or even "human beings". These general terms for the many are utilized alongside vague historical precedent, to prove the insurmountable difference between communities. Where the idea of the many is being called upon to justify independence and nationalism, it is also deployed to disapprove of the union of Hindu and Muslim communities. While Habib and Mohini understand their relationship as offering hope for national unity, the resistance to their relationship shows that their families view it with a lens of separation and thus create it as always already doomed. My argument here is that we need to understand this thwarted romance not as the tale of a Hindu and a Muslim who are not allowed to unite, but as subjects constituted as primarily Hindu and Muslim due to the resistance to their union. Before this, their attraction and involvement in politics meant that their affective sense of belonging was primarily to India and to Indian independence. Sara Ahmed has put it in these terms: "how we feel about others is what aligns us with a collective, which paradoxically 'takes shape' only as an effect of such alignments” (2004, 27). Although Mohini and Habib's relationship is one of great potential in terms of 
alignment with India, it becomes the vehicle that consolidates their difference. As Eqbal Ahmad has averred, citing Tagore, nationalism is an ideology of difference and so the very appropriation of nationalism in the service of anti-imperialism developed a politics that could divide the two communities $(2003,2$,).

Edward Said has posited that one can "declare oneself for difference (as opposed to sameness or homogenization) without at the same time being for the rigidly enforced and policed separation of populations into different groups" (1994, 81). What Said suggests is that the heterogeneity of people can be valued, and indeed patterns of distinction between groups be observed, but in ways that do not come to predetermine characteristics of groups in ways that homogenize. Difference can be recognized through the work of analysis, but should not be the foundation upon which all analysis is based. The rigidity that Said refers to is what emerges when difference becomes fetishized within any engagement with distinct groups, as though difference is always inherent and immutable. The proposed difference between Hindus and Muslims in the novel suggests that this particular aspect of difference is indeed inherent and immutable; the insistence that there is no mixing and mingling generates this rigidly enforced separation and is used in the service of separating populations into distinct groups. After Mohini's death Habib eventually marries divorcee Najma, and his younger sister Zohra marries Ahmed, a man of lower class. Initially, the Jamaluddin elders resist the idea of the siblings marrying a divorcee and a clerk respectively. They ultimately accept the unions because the spouses are Muslims and the marriages are therefore deemed affectively possible and healthy. Inter-Muslim difference, the novel suggests, can be overcome, but Hindu-Muslim difference proves too extreme to breach. Heart offers a narrative of the national context of 1930s-1940s 
colonial India in which difference, not unity, was setting the debate: a proposal that naturalizes moves towards Partition.

\section{Geographies of identity}

An insistence on the distinctness of Hindu and Muslim communities also emerges in the novel in relation to geography and cultural legacy, as characters interpret shared geography with the assumption of there being separate identity-based histories. This precludes any acknowledgement of the influences that operated between communities that lived in the same terrain. Affects of belonging are interpreted as upholding difference, although they show attachment to histories of fusion.

Yunas Samad has pointed out that the territorialized identity that emerged through the Pakistan movement was one of a specifically Indian Islam; that is, one that had fused with the Indo-Persian culture. Conversely, the exclusive focus on Islam as the sole source of identity works to erase this past $(2007,75)$. Any engagement with the complexities of history and cultural exchange poses a challenge to singular narratives of Islamic history and the assertion that communities did not mingle. However, in the novel separation is used to interpret the past so that the past comes to uphold this story of separation. As Jamaluddin explains to Sughra and Zohra:

You know how we Muslims came here; the first of our ancestors as far back as 712 A.D. You know how we ruled here for nearly eight hundred years, and you know how the country prospered and art culture [sic] flourished in that period. $(2004,41)$

To Jamaluddin, Muslim history is integral to the cultural development of India and spans over eight centuries of influence. His framing of Muslim history is one of glory: he associates ruling and empire with prosperity and cultural richness, and posits a 
history of Muslims in India, rather than one of Muslims generating an Indian Islam. There is no sense of fusion in his speech; he asserts the separateness of a "we" that rules and brings art, rather than discussing the art that emerges through cultural exchange. This is a religious identity -- one that happens to be in a specific location -not a territorial identity. In subtly insisting on this separation, Jamaluddin uses history to propose a distinctness between Muslim and Hindu Indians, while also offering a history and identity to which he and his daughters can feel attached with pride. Alyssa Ayres has emphasized how, in the years leading to Partition, Muslim nationalists drew links between the Arab invasion of Sindh in AD 712 and the belief that Muslims were thus a separate entity by birth and belief, and so deserved their own country (2009, 105-106). These links, as well as drawing on discourses of difference, also proposed an identification of Muslims within colonial India with Muslims of the Islamic empire and invasion. Jamaluddin clearly establishes this belonging to a particular history and, in light of Ayres's comment, his perspective can be understood as contributing to naturalizing the case for a separate country.

The novel continues to assert attachment to place when Sughra is profoundly affected by her visits to Delhi and Agra. She says, "I had a strange feeling that I had come to my real home. That feeling persisted when this morning I saw the tombs of Humayun and Nizamuddin" (2004, 320). Her cousin Fahmida empathizes, responding: "they are such an essential expression of your history and your culture that you feel as if you were part of them and they of you" $(2004,320)$. That these sites -- tombs of a Mughal ruler and Sufi saint, respectively -- hold such symbolic importance for Sughra associates her identification with Muslim history with a geographically understood declaration of "home". This identification sets the foundations for such thinking about the Pakistani nation, as we see here the capacity 
for transference of association with a notion of Islamic history as glorious, and one that is explicitly located and territorialized.

Nadia Abu El-Haj identifies a similar move, whereby interpretation of the past is used to prove the national origin story. El-Haj discusses how Israeli nationalism has utilized archaeological approaches to "prove" the nation's origin myth by producing evidence of a prior (historical) connection to the land (2001,3). This move to establish a historical connection to the land, and thus connect identity to a territory, can be seen in Sughra's sense of belonging to Delhi and her identification with Mughal and Muslim ancestry. She feels a connection to both Humayun and Nizamuddin, thus tying two facets of identity -- Arab and Muslim -- to Indian soil. In Agra she also feels an attachment to the Taj Mahal, an example of Indo-Persian Islamic culture. The belonging and sense of home Sughra expresses is thus one emerging from multiple locations, demonstrating the multi-faceted character of belonging. The dichotomy, then, is that this attachment becomes interpreted as a solely Muslim heritage, as outlined by Jamaluddin previously, and the Indo-Persian element of this history is ignored. In turn, these feelings of belonging motivate support for the Muslim League and the turn to Pakistan, because they refer to Islamic legacy; however, in this shift the belonging becomes reduced to a colonially-defined territory that is not concerned with such affects. Belonging and history may provide an origin myth, but fundamentally they do not control bureaucratic decision-making, which instead relies on the colonial census. Paradoxically, Partition itself contradicts the naturalization the novel uses to argue for it; Delhi and Agra, as Hindu-majority cities, were awarded to India, repressing the histories of cultural exchange in favour of population data. ${ }^{5}$ This contradiction is not explored by the novel, since Sughra's delight after her visit to Delhi and her belief in Pakistan are not shown to be in 
conflict. As such the novel upholds the move from affective attachment to a located Muslim history -- to the confirmation of Pakistan as a result of the bureaucratic process of drawing borders. As well as proposing that the connection between the origin myth of historical territorial identification and the case for Pakistan is a logical one, it does not question whether this logic will be upheld by Partition.

Affective attachments motivate the desire for Hindu-Muslim unity in the novel. The investment in Muslim history on Indian soil that is expressed suggests crossidentity attachments and interaction. However, such commitment to Hindu-Muslim unity is challenged when the historical legacy of such unity is undermined. This insistence makes the case for a singular Muslim history that has not fused with India, an argument that predetermines the failure of Hindu-Muslim unity at both personal and national levels. Historical continuity and glory is offered to Muslims, but not to Hindus and Muslims as Indians. These singular claims not only erase the crossfertilization and influence that made India rich, but in so doing naturalizes difference between communities, a move that proposes it will be easy to separate communities via partitioning land, because communities already exist as immutable and distinct nations. Attachments are thus interpreted through the assumption of singularity, a lens that denies their symbiotic nature. ${ }^{6}$ This in turn disguises the painful effects of separating communities who have shared land for centuries.

Sughra's attachment to location again demonstrates how affects were interpreted with a notion of singularity that could support moves towards Partition. It is worth noting that the final delineation of the borders was not published until after Independence. As such, the population's awareness of the ways that the material parameters of Pakistan would contradict the affective attachment to place was limited, if existent at all. ${ }^{7}$ The period that the novel's narrative covers allows it to idealize 
nationalist moves as this contradiction would not have been known at the point where the narrative ends.

\section{"Towards Pakistan!"}

While the extent to which geographical affects would be frustrated is not alluded to at all, the spectre of violence is raised and then repressed: the narrative anticipates violence but does not allow it to impede the nationalist vision. Shah Nawaz was aware of the human costs of Partition. Indeed, she volunteered at refugee camps set up to house those migrating into Pakistan, and directly participated in post-Partition rehabilitation efforts. The exclusion of the chaos of Partition from the novel's narrative is not therefore due to a lack of awareness of the disruption on her part. Instead it reflects the nationalist hope of the time, in which the expectation of violence and loss was secondary to a desire for independence and the creation of Pakistan, and is reflective of the emotionally-charged commitment to Pakistan that emerged during the 1940s and the optimism that existed for the nation's future.

The end of the novel begins to refer to the violence that is to come. The Jamaluddin siblings have gathered and are visited by an erstwhile close Hindu friend, Vijay, who declares:

But you want to separate ... Ah, can you not look into the future? [ ... ] Look, it comes, nearer and near it comes ... the separation and the shadow ... the darkest hour ... and the rift between us becomes a chasm ... and the chasm a sea ... a sea of blood and tears ... of tears and blood ... . (2004, 450)

Here Vijay warns of impending bloodshed, suggesting that the chasm of the borders that will be drawn at Partition will be confirmed in blood and tears. Through the 
$\underline{\text { multiple ellipses in Vijay's prediction, violence becomes an unspoken presence: it is }}$ pointed to by the ellipses, yet remains something that the novel itself cannot explicitly commit to narrative. This speech has a direct effect on Sughra, who withdraws to her room:

[She] looked out upon the western sky to see high up on the horizon the crescent moon with its accompanying star sailing in a sea of pale green, and she drew a breath of gladness and whispered, "The herald of Pakistan?" But her eyes dropped lower and the sunset surged into them in a flood of crimson and she shuddered and turned to go. $(2004,450)$

In this passage, Sughra's vision of the Pakistan flag is flooded out by the premonition of blood, as in Vijay's speech; her hope for Pakistan is challenged by this fear and expectation of violence. These two passages point towards the awareness within elite communities that violence would likely ensue. The characters allude to the approaching violence, are apprehensive of it, and the contemporary reader is reminded of what is to come in Partition's wake. The novel again gestures to the violence that will mar the nationalist vision, represented by the crimson surging over the symbol of the flag. Sughra's vision adds more weight to the connections Vijay makes between Partition and violence. However, this fear is not confirmed, and violence is alluded to rather than represented in the novel. In Tahir Naqvi's formulation of "unthinkability", he argues that the "unthinkability" of Partition's violence "conveys the more systematic disconnect in the final years of colonial rule between elite and popular constructions of territory, nationalism, and nationality" (2010, 61-62). As a realist novel that uses many contextual details, especially with regard to Cabinet plans and political negotiations, the absence, or repression, of violence is notable in reflecting the disconnection Naqvi outlines. 
The novel's conclusion, stressing individual affective bonds, confirms this "unthinkability". Berlant posits that fictional love plots can act as a "figure for optimism", and that being part of a couple or a family makes one "feel safe from the world, in the world, and for the world" $(2008,171)$. Indeed, the end of the novel provides closure in respect of the love plots of each of the Jamaluddin children. Both Habib and Zohra are married to Muslim partners, but Sughra remains estranged from her husband Mansur until Vijay's premonition and her own fear that violence will mar her nationalist hopes. Rather than considering the implications of her and Vijay's premonitions, she leaves Lahore for Multan to go to Mansur and they are reunited:

Then she looked up at him with radiant eyes, and she said:

"Henceforth we shall go forward together hand in hand, towards our goal."

“Towards Pakistan!” he said triumphantly. $(2004,451)$

Through her leaving Lahore to find Mansur and reunite with him, Sughra's fear of the violence that will accompany Partition and Pakistan's coming into being is quelled. The closing passages of the novel provide Sughra with the union that will make her feel safe from the world, or from what is to come. So much so that the "flood of crimson" and her downturned eyes are replaced with "radiant eyes" and a commitment to move forward towards the goal of Pakistan. Zohra and Habib are also affected by the fear and expectation of violence put forward by Vijay, and draw closer to their partners for comfort as Sughra leaves for Multan. Each of the siblings chooses to invest in their relationships as a method of providing individual security for the future and in relation to Partition. Sughra goes to Mansur as a direct response to her anticipation of bloodshed, which is then forgotten in the service of working towards Pakistan. The characters are aware of what is to come, but the narrative uses this fear 
of violence to consolidate affective attachment and national belonging as that which will alleviate the fear. In so doing, the affective attachment becomes the means by which anticipation of violence can be repressed.

\section{Conclusion}

Affect may produce the nation in The Heart Divided, and be used to consolidate the difference on which it relies, but the intelligibility and validity of the nation relies on geographical borders. Although Pakistan, as discourse, was generated by emotions, it was confirmed in geography through imperial knowledge and the political context at the time. Samad has argued that Pakistan emerged due to the exigencies of the transfer of power and the communal violence that was erupting due to uncertainty and anxieties $(2007,90)$. His view is that Partition was more about bureaucracy and political processes than affect. This article has aimed to highlight how, in The Heart Divided, emotions are used to make a case for the legitimacy of nationhood, without acknowledging its indebtedness to these processes.

As a realist novel written during the historical period it features, Heart can be taken as a document of its time; its occlusions and developing commitment to the realization of the new nation of Pakistan are telling in terms of specific attitudes to nationalism and independence in 1930s-40s colonial India. ${ }^{8}$ One consequence of Shah Nawaz's untimely death in 1948 was that she never wrote the planned sequel to Heart, a novel in which she intended to chart events from 1942 onwards (Shahnawaz 2002, 222). Had Shah Nawaz lived, she may well have attempted to narrativize the violence and dislocation that accompanied Partition, as well as its contradictions, and place the events of Heart within a broader political and temporal trajectory. However, that such a sequel does not exist is one of the factors that make Heart such a 
compelling novel to analyse, and it is significant that she ended the first volume before Partition. The events of Partition are consequently framed as a sequel and not as embedded within what had emerged thus far. The novel thus creates in its structure a separation between affect and bureaucracy. It stops short of Partition itself, ending the narrative with a sense of victory and inevitability that Pakistan must be achieved, but without allowing the narrative to chart the violence of its becoming or the way that affects were frustrated by, and subordinated to, the borders of the Radcliffe Line. The text thus acts as a Partition story (because it acts as a rationale for Partition) that does not assess the atrocities and contradictions of Partition. This is where we find the nationalist ideology of the novel, since it does not commit to narrative the disjuncture between the goals and aspirations of the affective political movement and the reality of Partition. Therefore the novel puts forward an idealized vision of the nation, one that is in line with affect and belonging but does not embody the tensions that exist between affect and bureaucracy within the nationalist project.

\section{Notes on contributor}

Humaira Saeed completed her $\mathrm{PhD}$ at the University of Manchester; her thesis is concerned with the ways in which the trauma of the Partition of India has lasting ramifications for the ways in which Pakistan and Pakistani identities are narrativized in cultural texts. She has published articles on Partition and Pakistani film and coedited a special issue of Women: A Cultural Review on Transnational Feminisms. She maintains a scholarly and activist interest in the ways in which queer modes of belonging become asserted through racialized attachments to the nation-state, and is a member of the Decolonizing Sexualities research network.

\section{References}

Ahmad, Eqbal. 2003. Confronting Empire. Lahore: Vanguard Books.

Ahmed, Akhbar S. 1997. Jinnah, Pakistan and Islamic Identity. London: Routledge. 
Ahmed, Sara. 2000. Strange Encounters: Embodied Others in Postcoloniality. London: Routledge.

Ahmed, Sara. 2004a. "Collective Feelings or, the Impressions Left by Others." Theory, Culture \& Society 21 (2): 25-42.

Ahmed, Sara. 2004b. The Cultural Politics of Emotions. London: Routledge.

Anderson, Benedict. 2006. Imagined Communities. Rev. ed. London: Verso.

Ayres, Alyssa. 2009. Speaking Like a State: Language and Nationalism in Pakistan. Cambridge: Cambridge University Press.

Berlant, Lauren. 2008. The Female Complaint. London: Duke University Press.

Bruschi, Isabella. 2010. Partition in Fiction: Gendered Perspectives. New Delhi: Atlantic Publishers.

Chatterjee, Partha. 1993. The Nation and Its Fragments: Colonial and Postcolonial Histories. Princeton, NJ: Princeton University Press.

Chatterjee, Partha. 2001. Nationalist Thought and the Colonial World: A Derivative Discourse. Minnesota: University of Minnesota Press.

El-Haj, Nadia Abu. 2001. Facts on the Ground: Archaeological Practice and Territorial Self-Fashioning in Israeli Society. London: University of Chicago Press.

Grossberg, Lawrence. 1992. We Gotta Get out of This Place: Popular Conservatism and Postmodern Culture. New York: Routledge.

Handelman, Don. 2007. "The Cartesian Divide of the Nation-State: Emotion and Bureaucratic Logic.” In The Emotions: A Cultural Reader, edited by Helena Wulff, 119-140. Oxford: Berg.

Hosain, Attia. 1998. Sunlight on a Broken Column. London: Virago.

Jalal, Ayesha. 2010. The Sole Spokesman: Jinnah, the Muslim League and the Demand for Pakistan. Lahore: Sang-e-Meel Publications. 
Naqvi, Tahir Hasnain. 2010. "The Politics of Commensuration: The Violence of Partition and the Making of the Pakistani State." In Beyond Crisis: ReEvaluating Pakistan, edited by Naveeda Khan, 61-88. London: Routledge.

Said, Edward. 1994. The Politics of Dispossession: The Struggle for Palestinian SelfDetermination, 1969-1994. London: Chatto and Windus.

Samad, Yunas. 2007. "Pakistan: From Minority Rights to Majoritarianism.” In Faultlines of Nationhood: Cross Border Talks. Gyanendra Pandey and Yunas Samad, 63-138. New Delhi: Roli Books.

Scott, Joan. 1991. “The Evidence of Experience.” Critical Inquiry 17 (4): 773-797. Shahnawaz, Jahanara. 2002. Father and Daughter: A Political Autobiography. Karachi: Oxford University Press.

Shah Nawaz, Mumtaz. [1957] 2004. The Heart Divided. New Delhi: Penguin. Shamsie, Muneeza. 2005. Introduction to And the World Changed: Contemporary Stories by Pakistani Women. New Delhi: Women Unlimited. xi-xx Sidhwa, Bapsi. [1988] 1989. Ice-Candy Man. New Delhi: Penguin Books. Singh, Khushwant. 1956. Train to Pakistan. London: Chatto and Windus. Zaman, Niaz. 2001. A Divided Legacy: The Partition in Selected Novels of India, Pakistan, and Bangladesh. New Delhi: Manohar Publishers.

\section{Notes}

\footnotetext{
${ }^{1}$ Radcliffe used data from the 1941 colonial census to allocate districts as Muslim or Hindu majority. He was required to take population information and transfer it into a cartographic articulation. Cultural identity of place, and affects towards place and other people were disregarded by the remit of the Radcliffe Line.

${ }^{2}$ For example Sidhwa's Ice-Candy Man (1989) and Singh's Train to Pakistan (1956).
} 
${ }^{3}$ See, for example, Berlant (2008), Ahmed (2000, 2004a, 2004b), and Anderson (2006).

${ }^{4}$ Grossberg proposes that powerful affective investments must be ideologically legitimated through an "excess which differentiates it from other sites" $(1992,86)$. In this context, those who support the Muslim League do so because the League offers something more than Congress. Grossberg continues that "[t]his excess, while ideologically constructed is beyond ideological challenge because it is called into existence affectively" $(1992,86)$.

${ }^{5}$ The same is true of sites of Hindu cultural significance that remain in Pakistan, for example the Hinglaj Mata temple in Hingol, Balochistan, which features in the Ramayana, and the Katasraj temples in Chakwal district Punjab, from the Mahabharata.

${ }^{6}$ See also Chatterjee (1993), who argues that the notion of singular national histories cannot be upheld, especially across distinct regions of India, and goes on to argue that an insistence on singularity has proven to be divisive.

${ }^{7}$ There is some difference of opinion regarding when the Radcliffe award that delineated the new nations' borders was published. Ahmed (1997) cites 16 August, Bruschi (2010) 17 August, and Jalal (2010) 18 August. Although these dates differ, they all concur that the award was published after the creation of Pakistan on 14 August, and that India and Pakistan emerged as two nations unsure of their exact territorial demarcation. Confusion regarding where the borders would fall is often considered to have exacerbated communal violence in the months leading to Partition (see Jalal 2010, Zaman 2001). ${ }^{8}$ See Shahnawaz (2002) for more detail. 